\section{(2)} OPEN ACCESS

\title{
Effect of renin-angiotensin system blocker on COVID-19 in young patients with hypertension
}

\author{
Mustafa Kuzeytemiz 지 , Erhan Tenekecioglu
}

Additional supplemental material is published online only. To view, please visit the journal online (http://dx. doi.org/10.1136/jim-2021002036).

Cardiology, Bursa Yüksek Hastanesi, Bursa, Turkey

\section{Correspondence to} Dr Mustafa Kuzeytemiz, Cardiology, Bursa Yüksek İhtisas Eğitim ve Araştırma Hastanesi, Bursa, Turkey; mustafakuzeytemiz@gmail. com

Accepted 5 November 2021 İhtisas Eğitim ve Araştırma

\begin{abstract}
Hypertension is found frequently in patients with COVID-19 and is often treated with ACE inhibitors (ACEIs) and angiotensin receptor blockers (ARBs). SARS-CoV-2, the pathogen of COVID-19, binds to the receptors of ACE2 to enter the alveolar cells, raising questions on whether these drugs are salutary or harmful with respect to any propensity for COVID-19 or to disease prognosis. We investigated the impact of ACEI/ARB and the clinical prognosis of patients with hypertension with COVID-19. In this study, 250 patients with hypertension $(<45$ years old) with COVID-19 were recruited. None of these patients had any chronic disease except for hypertension. The study population was grouped according to antihypertensive medication: ACEI/ ARB user and non-ACEI/ARB user. Patients were followed for clinical prognosis and biochemical and radiological findings during their hospital stay. Adverse cardiovascular event (myocardial infarction, all-cause death, stroke), transfer to the intensive care unit, severity of symptoms during the treatment course, length of hospital stay and effort capacity in the treadmill stress test were recorded. During hospital stay, there was no significant difference in terms of length of hospital stay, medication for COVID-19, left ventricular ejection fraction on echocardiography and metabolic equivalents in the treadmill stress test between patients treated with and without ACEI/ARB. During treatment of COVID-19, there was no significant difference in clinical adverse event, effort capacity and clinical course between patients with and without ACEI/ ARB. It appears that patients with COVID-19 may continue to use ACEI/ARB or that ACEI/ARB may be added safely to their antihypertensive treatment.
\end{abstract}

\section{INTRODUCTION}

Check for updates

(c) American Federation for Medical Research 2022. No commercial re-use. See rights and permissions. Published by BMJ.

\begin{tabular}{l}
\hline To cite: Kuzeytemiz M, \\
Tenekecioglu E. \\
J Investig Med Epub \\
ahead of print: [please \\
include Day Month Year]. \\
doi:10.1136/jim-2021- \\
002036
\end{tabular}

To cite: Kuzeytemiz M, Tenekecioglu $\mathrm{E}$

J Investig Med Epub ahead of print: [please doi:10.1136/jim-2021-
For the past 2 years, the whole world has suffered from a pandemic caused by SARS-CoV-2, the virus that causes COVID-19, first recorded in Wuhan, Hubei Province, China in December 2019. ${ }^{1}$ Once it has entered the human body, the virus uses a membrane protein, the pulmonary ACE2 receptor, to enter the human alveolar cells in the lungs. On account of this mechanism, from the beginning of the outbreak, there have been debates about the role of ACE inhibitors/angiotensin receptor blockers (ACEIs/ ARBs) in COVID-19, since they use angiotensin receptors in their pharmacokinetic pathway. ${ }^{2}$

\section{Significance of this study}

What is already known about this subject?

- COVID-19 is a pandemic that has caused deaths worldwide.

- Hypertension is an important risk factor of death due to COVID-19.

- The use of ACE inhibitors/angiotensin receptor blockers (ACEIs/ARBs) in patients with COVID-19 remains controversial.

What are the new findings?

- The use of ACEI/ARB is safe for patients with COVID-19.

- The use of ACEI/ARB has no extra benefit compared with other antihypertensive drugs.

- Deaths from COVID-19 are independent of the antihypertensive drug used and are associated with high troponin, D-dimer and $\mathrm{C}$ reactive protein levels.

How might these results change the focus of research or clinical practice?

- The questions in the mind of clinicians and patients will be answered.

- The benefits of ACEI/ARB, which are also used in many cardiovascular diseases other than hypertension, will not lose its significance.

- The increased mortality among the elderly population is possibly due to the frequent use of these drugs.

- ACEIs/ARBs have been implicated for increase in mortality of patients with COVID-19, therefore young patients with hypertension without any other chronic diseases were recruited in this study in order to demonstrate the safety of this class of drugs.

Evidence from several studies has shown that elderly patients with COVID-19 and cardiovascular diseases, including hypertension, are at risk of severe progression of an infectious disease. The molecular mechanism responsible for the increased disease severity in patients with these comorbidities is not fully understood; however, some previous studies have suggested an apparent role of ACE2. ${ }^{3}$

During treatment, ACEIs/ARBs increase the amount of angiotensin receptors, which 
theoretically could increase binding of SARS-CoV-2 to the lung cells and could lead to more diffuse and severe lung injury. However, some experimental studies have also revealed that ACE2 protects the lung and other ACE2bearing tissues from a destructive injury caused by the virus. $^{4}$

In our study, we investigated the effect of ACEI/ARB on clinical prognosis, laboratory parameters and findings on imaging modalities in patients with COVID-19.

\section{METHODS}

We performed a retrospective review of the medical records of hospitalized patients with COVID-19 admitted to our institution between April 2020 and June 2020 (online supplemental file 1). Patients' files were scanned for any adverse clinical event (decrease in functional capacity, allcause mortality, reinfection) during their hospital stays. Verbal and written informed consents were obtained from all patients or patients' family members.

We extracted data on clinical symptoms and signs, laboratory parameters, transthoracic echocardiography findings and results of the treadmill stress test performed before hospital discharge.

In our study, 250 patients with COVID-19 diagnosis and hypertension were included. The patients recruited to the study were selected from our hospitalized patient population who underwent coronary angiography. To exclude any impact on inflammatory parameters, heart functions and biochemical variables, patients who had coronary angiography in their medical history and had no coronary artery disease at coronary angiography (CAG) were selected. Patients were grouped according to antihypertensive medication, whether or not ACEIs/ARBs were used in the treatment of hypertension. Group 1 included patients with COVID-19 with antihypertensive treatment, including ACEI/ARB, and group 2 included patients with COVID-19 treated with any hypertensive drug except ACEI/ARB. Subjects with any of the following diseases were excluded from the study: coronary artery disease, heart failure, chronic kidney disease, chronic obstructive pulmonary disease, cases aged $>45$ years old, any chronic diseases under treatment such as cancer, infiltrative diseases, muscular dystrophies, inflammatory bowel disease, liver disease, etc.

All patients had a diagnosis of COVID-19 that was verified by a commercial real-time PCR kit used to detect SARS-CoV-2. After the diagnosis of COVID-19, all patients received treatment for COVID-19 according to the guidelines and treatment protocols established by the Turkish Health Ministry. During the analysis, we recruited cases with X-ray findings of COVID-19 pneumonia despite a negative PCR result and cases with increased $C$ reactive protein (CRP), D-dimer and fibrinogen values in the biochemical study.

During treatment in the hospital, patients were followed for fever, blood pressure, any worsening in breathing, blood parameters (hemogram, biochemical parameters, and cardiac biomarkers such as cardiac troponin, creatine kinase myocardial band (CK-MB) and N-terminal-pro-B type natriuretic peptide (NT-proBNP)), inflammatory parameters (high-sensitive CRP, D-dimer and fibrinogen) and pulmonary X-ray graph. During treatment in the hospital, after their clinical status has stabilized (no fever in the last 24 hours, normal breathing status, etc), transthoracic echocardiography assessment was performed in all cases to evaluate ventricular and atrial functions and any pericardial disease. At the end of treatment, before hospital discharge, all cases performed a treadmill stress test to determine their effort capacity. The treadmill stress test was conducted according to the Duke criteria in the relevant guidelines. ${ }^{5}$

\section{Statistical analysis}

Continuous variables were expressed as mean \pm SD for normally distributed variables, and median $\pm \mathrm{IQR}$ and discrete variables were expressed in percentages, respectively. $\chi^{2}$ test or Fisher's exact test was used to compare categorical variables between the groups. Student's t-test was performed to compare continuous variables. $\mathrm{P}<0.05$ was considered statistically significant. The number of nonmissing values for each variable was used in the statistical analysis using SPSS V.21.0. We used the missing listwise subcommand to exclude data in case of a missing value on any variable in the list. In the regression analysis, if there are missing values in any of the variables on the 'var' subcommand, the entire case was excluded from the analysis (listwise deletion of missing data). All statistical analyses were performed using the Statistical Package for the Social Sciences V.21.0 software for Mac.

\section{RESULTS}

In our study, 250 patients with hypertension were recruited, of whom 134 were taking ACEI/ARB. Women $(n=110$ patients) constitute $44 \%$ of the total study population. During in-hospital follow-up, $18.4 \%(\mathrm{n}=46$ patients) of the patients died, of whom 27 cases were from the ACEI/ARB group and 19 from the non-ACEI/ARB group.

The treatment protocol applied to patients with COVID-19 by the Turkish Health Ministry was as follows: favipiravir $2 \times 600 \mathrm{mg}$, azithromycin $2 \times 500 \mathrm{mg}$, prednisone $1 \mathrm{mg} / \mathrm{kg}$ and ibuprofen $600 \mathrm{mg} 1 \times 1$ for at least 5 days.

Baseline characteristics, laboratory findings and in-hospital course of patients receiving or not receiving ACEI/ $\mathrm{ARB}$ are given in table 1 . The mean age and gender ratio were comparable in both study groups. All other baseline characteristics and medical treatments were also comparable between the groups ( $p>0.05$, for each). All laboratory results, including blood parameters and biochemical findings, were found similar in both patient groups. There was no difference in the cumulative survival of the study groups with and without ACEI/ARB $(p=0.68$; figure 1$)$. The frequency of intensive care unit (ICU) admission, endotracheal intubation and in-hospital mortality was found comparable in the study groups with and without ACEI/ ARB ( 3 cases $(2.5 \%)$ vs 3 cases $(2.8 \%), \mathrm{p}=0.97 ; 34$ cases $(25 \%)$ vs 27 cases $(23 \%), \mathrm{p}<0.79$; and 26 cases $(19 \%)$ vs 20 cases $(17 \%), p=0.19$, respectively; table 2 ). On transthoracic echocardiography, no thrombus was detected within the left ventricle of the patients. However, on lung CT scans, 11 cases had thrombus in the branches of the pulmonary arteries.

The study population was divided into two groups: survivor group and non-survivor group (table 3). Use of ACEI/ARB was modestly higher in the survivor group 


\begin{tabular}{|c|c|c|c|}
\hline Characteristics & $\begin{array}{l}\text { ACEI/ARB } \\
(n=134)\end{array}$ & $\begin{array}{l}\text { Non-ACEI/ARB } \\
(n=116)\end{array}$ & $P$ value \\
\hline Age (years) & $36.6 \pm 6.1$ & $37.3 \pm 6.0$ & 0.62 \\
\hline Gender (male/female) & $77 / 57$ & $63 / 53$ & 0.74 \\
\hline $\begin{array}{l}\text { Admission systolic blood } \\
\text { pressure (mm Hg) }\end{array}$ & $138 \pm 23$ & $126 \pm 21$ & 0.52 \\
\hline $\begin{array}{l}\text { Admission diastolic blood } \\
\text { pressure }(\mathrm{mm} \mathrm{Hg})\end{array}$ & $78 \pm 14$ & $72 \pm 13$ & 0.29 \\
\hline Smoking & $10(7.3)$ & $11(9.2)$ & 0.45 \\
\hline \multicolumn{4}{|l|}{ Laboratory data } \\
\hline White cell count $\left(\times 10^{9} / \mathrm{L}\right)$ & $7.8 \pm 2.6$ & $7.4 \pm 2.3$ & 0.54 \\
\hline Hemoglobin (mg/dL) & $23,59 \pm 3.06$ & $21.91 \pm 3.06$ & 0.60 \\
\hline Hematocrit & $40.2 \pm 5$ & $39.6 \pm 5$ & 0.59 \\
\hline Platelets, $\left(\times 10^{9} / \mathrm{L}\right)$ & $196 \pm 46$ & $207 \pm 64$ & 0.38 \\
\hline Sedimentation & $45.8 \pm 27.8$ & $47.3 \pm 26.7$ & 0.88 \\
\hline Glucose (mg/dL) & $90.8 \pm 9.2$ & $88.7 \pm 9.2$ & 0.32 \\
\hline Blood urea nitrogen (mg/dL) & $14.1 \pm 5.2$ & $14.2 \pm 5.6$ & 0.24 \\
\hline Creatinine (mg/dL) & $0.95 \pm 0.6$ & $0.81 \pm 0.18$ & 0.45 \\
\hline Uric acid (mg/dL) & $6.1 \pm 1.9$ & $4.9 \pm 1.3$ & 0.48 \\
\hline Lactate dehydrogenase (U/L) & $478 \pm 276$ & $442 \pm 175$ & 0.32 \\
\hline AST (IU/L) & $25 \pm 10.6$ & $24.5 \pm 9.5$ & 0.82 \\
\hline ALT (IU/L) & $33 \pm 19$ & $34 \pm 19.5$ & 0.84 \\
\hline $\mathrm{C}$ reactive protein (mg/dL) & $38 \pm 79$ & $40 \pm 84$ & 0.92 \\
\hline Fibrinogen (mg/L) & $549 \pm 138$ & $521 \pm 152$ & 0.45 \\
\hline D-dimer (mg/L) & $1.14 \pm 2.1$ & $1.24 \pm 2.3$ & 0.81 \\
\hline Creatine kinase $(\mathrm{mg} / \mathrm{dL})$ & $114 \pm 47$ & $106 \pm 46$ & 0.40 \\
\hline CK-MB (mg/dL) & $0.88 \pm 0.51$ & $0.72 \pm 0.43$ & 0.82 \\
\hline Troponin $(\mu \mathrm{g} / \mathrm{mL})$ & $13.1 \pm 40$ & $14.3 \pm 43$ & 0.93 \\
\hline ProBNP (pg/mL) & $56 \pm 32$ & $56.7 \pm 42$ & 0.78 \\
\hline \multicolumn{4}{|l|}{$\begin{array}{l}\text { Antihypertensive medications, } \\
\mathrm{n}(\%)\end{array}$} \\
\hline Calcium channel blockers & $45(33.2)$ & $28(24.3)$ & 0.17 \\
\hline Beta blockers & $43(31.5)$ & $32(27.2)$ & 0.41 \\
\hline \multicolumn{4}{|l|}{ Other medications, n (\%) } \\
\hline Anticoagulant therapy & $7(4.6)$ & $8(6.9)$ & 0.31 \\
\hline Aspirin & 45 (32.9) & 34 (29.5) & 0.09 \\
\hline Furosemide & $9(7.2)$ & $5(4.4)$ & 0.30 \\
\hline Statins & $32(23.2)$ & $18(15.8)$ & 0.28 \\
\hline $\begin{array}{l}\text { Left ventricular ejection } \\
\text { fraction }(\%)\end{array}$ & $58 \pm 12$ & $55 \pm 10$ & 0.25 \\
\hline Metabolic equivalents & $7 \pm 3$ & $8 \pm 4$ & 0.18 \\
\hline
\end{tabular}

ACEI, ACE inhibitor; ALT, alanine transaminase; ARB, angiotensin receptor blocker; AST, aspartate aminotransferase; BNP, brain natriuretic peptide; CK$M B$, creatine kinase myocardial band.

than in the non-survivor group (137 cases (67.1\%) vs 26 cases $(56.7 \%), p=0.076)$. Laboratory findings showed that patients who did not survive following COVID-19 infection had higher white cell count, plasma glucose, D-dimer and CRP, while their lymphocyte levels were significantly lower, compared with the survivor group.

The independent predictors associated with in-hospital mortality were assessed by univariable and multivariable logistic regression analyses. At the end of the univariable analysis, four variables were found to be statistically significant with in-hospital mortality: D-dimer, white cell count, glucose and CRP. These variables, which were included in the multivariable analysis, are shown in table 4 . The

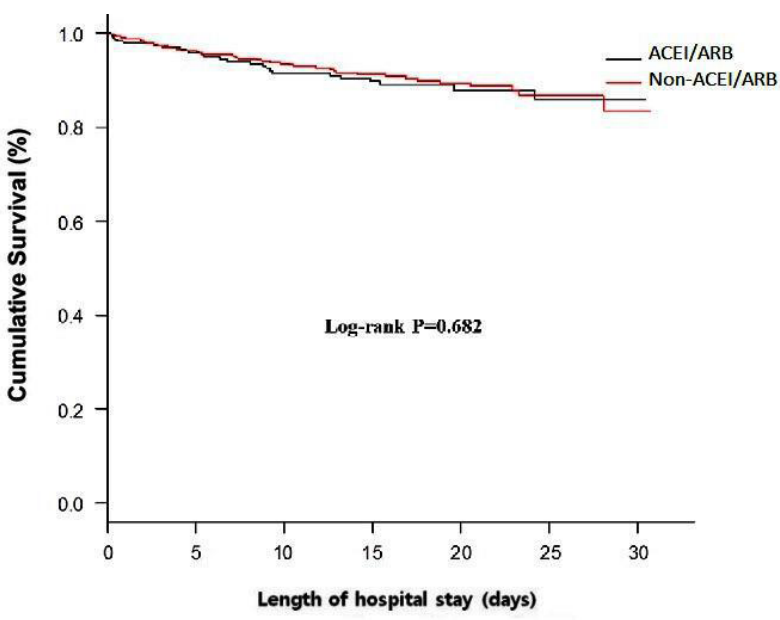

Figure 1 Survival curves analysis. When the survival curves were compared with the log-rank test, no significant difference was observed between the groups ( $p=0.682)$. ACEl, ACE inhibitor; ARB, angiotensin receptor blocker.

multivariable analysis showed that D-dimer and CRP were independent predictors of in-hospital mortality.

A progressive graded exercise treadmill test was performed after the treatment of patients has concluded, preceding hospital discharge. The test duration was $12 \mathrm{~min}$ and the speed was kept constant at 2 miles/hour, while the grade increased by $2 \%$ every $2 \mathrm{~min}$ until either the test duration was completed or the subject elected to stop due to difficulty in breathing or dyspnea. All subjects in both study groups completed the exercise test. There were no rhythm disturbances and ST segment depression/elevation in terms of cardiac ischemia during the treadmill stress test. The metabolic equivalents (METs) reached during the stress test were comparable in the study groups with and without ACEI/ARB $(p=0.18)$. Both study groups with and without ACEI/ARB revealed comparable left ventricular ejection fraction on transthoracic echocardiography (table 1).

There were differences in blood inflammatory parameters, X-ray findings and effort capacity during the treadmill test between patients treated in the short term (around 1 week) and those treated in the long term ( $>1$ week). The cases treated around 1 week had significantly lower CRP, D-dimer, fibrinogen and NT-proBNP values compared with the cases treated $>1$ week. After the cases were grouped

Table 2 Symptoms and clinical progression

\begin{tabular}{lccl}
\hline Variables & $\begin{array}{l}\text { ACEI/ARB, } \\
\mathbf{n}(\%)\end{array}$ & $\begin{array}{l}\text { Non-ACEI/ARB, } \\
\mathbf{n}(\%)\end{array}$ & P value \\
\hline Fever & $134(100)$ & $116(100)$ & 1.00 \\
Cough & $123(92)$ & $96(83)$ & 0.98 \\
Dyspnea & $107(80)$ & $86(74)$ & 0.82 \\
Sore throat & $43(32)$ & $46(40)$ & 0.35 \\
Headache & $58(43)$ & $46(40)$ & 0.91 \\
ICU admission & $3(2.5)$ & $3(2.8)$ & 0.97 \\
Endotracheal intubation & $34(25)$ & $27(23)$ & 0.79 \\
Death & $26(19)$ & $20(17)$ & 0.19 \\
\hline
\end{tabular}

ACEI, ACE inhibitor; ARB, angiotensin receptor blocker; ICU, intensive care unit. 
Table 3 Characteristics of survivor and non-survivors with hypertension hospitalized with COVID-19

\begin{tabular}{|c|c|c|c|}
\hline Characteristics & $\begin{array}{l}\text { Survivor } \\
(n=204)\end{array}$ & $\begin{array}{l}\text { Non-survivor } \\
(\mathrm{n}=46)\end{array}$ & $P$ value \\
\hline Age (years) & $37 \pm 4$ & $40 \pm 6$ & 0.07 \\
\hline Gender (male/female) & $117 / 87$ & $19 / 27$ & 0.65 \\
\hline Smoking & $18(8.7)$ & $5(10.4)$ & 0.25 \\
\hline \multicolumn{4}{|l|}{$\begin{array}{l}\text { Antihypertensive medications, } \\
\mathrm{n}(\%)\end{array}$} \\
\hline ACEI/ARB & $137(67.1)$ & $26(56.7)$ & 0.076 \\
\hline Calcium channel blockers & $45(22.2)$ & $17(36.0)$ & 0.23 \\
\hline Beta blockers & $68(33.5)$ & $14(30.9)$ & 0.87 \\
\hline \multicolumn{4}{|l|}{ Other medications, n (\%) } \\
\hline Anticoagulant therapy & $13(6.3)$ & $4(7.9)$ & 0.43 \\
\hline Aspirin & $63(31.1)$ & $17(37.3)$ & 0.056 \\
\hline Statins & $34(16.6)$ & $11(23.4)$ & 0.092 \\
\hline Furosemide & $10(5.0)$ & $3(7.2)$ & 0.08 \\
\hline \multicolumn{4}{|l|}{ Laboratory data } \\
\hline White cell count $\left(\times 10^{9} / \mathrm{L}\right)$ & $5.10 \pm 2.12$ & $8.93 \pm 4.31$ & 0.004 \\
\hline Hemoglobin (mg/dL) & $11.9 \pm 1.3$ & $12.1 \pm 1.7$ & 0.53 \\
\hline Hematocrit & $41.2 \pm 4.0$ & $40.9 \pm 3.9$ & 0.37 \\
\hline Glucose (mg/dL) & $98 \pm 34$ & $119 \pm 49$ & 0.045 \\
\hline Creatinine (mg/dL) & $1.11 \pm 0.19$ & $1.60 \pm 0.78$ & $<0.005$ \\
\hline Uric acid (mg/dL) & $6.0 \pm 1.4$ & $4.7 \pm 1.2$ & 0.68 \\
\hline AST (IU/L) & $22 \pm 9$ & $24 \pm 8.8$ & 0.79 \\
\hline ALT (IU/L) & $30 \pm 12$ & $32 \pm 11$ & 0.94 \\
\hline Lactate dehydrogenase (U/L) & $406 \pm 132$ & $469 \pm 187$ & 0.09 \\
\hline$C$ reactive protein $(\mathrm{mg} / \mathrm{dL})$ & $27.9 \pm 38.7$ & $119.1 \pm 75.8$ & 0.02 \\
\hline D-dimer (mg/L) & $1.39 \pm 0.3$ & $4.18 \pm 29$ & 0.02 \\
\hline Creatine kinase (mg/dL) & $93 \pm 87$ & $118 \pm 68$ & 0.54 \\
\hline CK-MB (mg/dL) & $0.8 \pm 0.5$ & $0.8 \pm 0.5$ & 0.82 \\
\hline Troponin & $12.1 \pm 9.0$ & $13.1 \pm 8.2$ & 0.66 \\
\hline ProBNP & $49 \pm 34$ & $57 \pm 31$ & 0.12 \\
\hline Hospital stay, days & $7 \pm 4$ & $12 \pm 8$ & 0.086 \\
\hline
\end{tabular}

ACEI, ACE inhibitor; ARB, angiotensin receptor blocker; AST, aspartate aminotransferase.

according to treatment duration, we observed that the cases with treatment duration of 1 week had less diseased area on X-rays, at least visually. Compatible with the blood inflammatory parameters and X-ray findings, patients with 1-week treatment had significantly higher METs compared with subjects treated $>1$ week.

\section{DISCUSSION}

The main findings of the present study are as follows: (1) in patients with COVID-19, ACEIs/ARBs do not have any significant impact on in-hospital treatment phase in terms of ICU admission frequency, endotracheal intubation and in-hospital mortality; (2) no negative or positive influence of ACEI/ARB was detected on the effort capacities of patients with COVID-19; and (3) the multivariable analysis revealed that D-dimer and CRP were independent predictors of in-hospital mortality in patients with COVID-19.

During the previous outbreak of severe acute respiratory syndrome (SARS) and Middle East Respiratory Syndrome (MERS) infections, hypertension was ascertained as one of the significant indicators of increased mortality in cases encountering such virulent infections. ${ }^{67}$ Concordantly, hypertension has been shown to be one of the substantial risk factors that increases the risk of mortality in COVID19. ${ }^{8}$ Given the uncertainty on the exact mechanism between elevated arterial pressure and increased mortality, it was assumed that an exuberant renin-angiotensin system (RAS) activation may trigger acute lung injury by provoking inflammatory reactions (cytokine storm) and prompting vasoconstriction, and moreover cell contraction. ${ }^{910}$

Numerous trials have revealed that patients with cardiovascular diseases are at considerable risk of complications from COVID-19. ${ }^{11-13}$ Although the cause of the escalated adverse events from COVID-19 lacks clarity, the aggregated impact of diabetes, hypertension, smoking, male gender and obesity is estimated to have a role in the dreadful outcomes of COVID-19 and concomitant cardiovascular diseases. ${ }^{14} 15$ Huang et $a l^{16}$ emphasized that the most prevalent comorbidities along with COVID-19 were hypertension (30\%), diabetes (19\%) and coronary heart disease (8\%), which are also related to acute respiratory distress syndrome (ARDS) in COVID-19. ${ }^{17}$ Moreover, in Italy, $75 \%$ of cases who died due to COVID-19 had hypertension. ${ }^{18}$ Nevertheless, it remains debatable whether there is a causal interrelationship between severity of COVID-19 and hypertension due to the fact that hypertension is so common in the older population, who are at risk of emerging life-threatening COVID-19. To alleviate the impact of any confounder on developing severe and burdensome COVID-19, such as older age, cardiovascular diseases, immunosuppression and chronic inflammatory diseases, subjects younger than 45 years and those without any chronic medical disorders, except hypertension, were included in this retrospective study.

ACE2 is a transmembrane protein expressed in the airway and type 2 pneumocytes in the lung. ACE2 was also found to be increased in the renal tubules of patients with diabetes. ${ }^{19}$ ACE2 is mainly located on the external surface of cells and converting angiotensin II, a vasoconstrictor peptide, to angiotensin (1-7), a vasodilator peptide. ${ }^{20} 21$ ACE2 in the circulating plasma, sourced from the endothelial cells, indicates hypertension and heart failure. ${ }^{22} 23$ Besides its circulation regulatory function, ACE2 also has some immune modulatory effects; in vascular and lung inflammation, ACE2 interacts with

Table 4 Univariable analysis and multivariable model for in-hospital mortality

\begin{tabular}{llllll}
\hline Univariable analysis & P value & OR $(95 \% \mathrm{Cl})$ & Multivariable analysis & P value & OR $(95 \% \mathrm{Cl})$ \\
\hline D-dimer & $<0.01$ & $1.00(0.98$ to 1.00$)$ & D-dimer & - & - \\
White cell count & 0.001 & $1.03(1.02$ to 1.50$)$ & - & - & $1.03(1.00$ to 1.45$)$ \\
Glucose & 0.035 & $1.00(1.00$ to 1.12$)$ & - & - & \\
Creatinine & 0.001 & $1.01(1.00$ to 1.35$)$ & - & 0.016 & $2.34(1.09$ to 12.54$)$ \\
C reactive protein & 0.001 & $5.36(2.32$ to 16.75$)$ & C reactive protein & & \\
\hline
\end{tabular}


macrophages. ${ }^{24}$ Moreover, by decreasing angiotensin II, which is a pro-inflammatory and pro-oxidant peptide, ACE2 has antiinflammatory effects as well. ${ }^{25}{ }^{26}$ SARS-CoV-2 binds to ACE2 in order to enter the lung cells during lung inflammation. ACEIs/ARBs have such an effect of increase in ACE2, which theoretically means increasing the coupling of the virus to the cells and exacerbating lung injury. The increase in angiotensin II in patients with COVID-19 compared with healthy subjects has been reported previously. ${ }^{27}$

On the other hand, as mentioned above, ACE2 renders anti-inflammatory effects particularly in the lungs. ${ }^{28-30}$ During ACEI inh/ARB exposure, an increment in circulatory ACE2 may increase binding SARS-CoV-2 which will decrease the virus' potential to injure the lungs and other ACE2-expressing tissues. ${ }^{31}$ RAS inhibitors have been previously demonstrated to decrease mortality in sepsis. ${ }^{4}$ Re $e t a l^{32}$ reported that, in patients with COVID-19 with hypertension, ACEI/ARB therapy mitigated the inflammatory response, probably by hampering the production of interleukin 6 (IL-6), in line with preceding data that treatment with ACEI and ARB diminished lipopolysaccharide-induced pneumonic injury.

In the present study, there were no significant differences in inflammatory markers between the groups with and without ACEI/ARB therapy. Not only the inflammatory markers, but also clinically there was no difference in symptom severity, duration of symptoms and treatment between cases with and without ACEI/ARB. With regard to effort capacity, patients with and without ACEI/ARB demonstrated comparable exercise duration and MET.

Age, D-dimer and lactate dehydrogenase have been found to be significant predictors of mortality in COVID-19 cases. With aging, $\mathrm{B}$ and $\mathrm{T}$ cell migration from primary to secondary lymphoid organs is abated. ${ }^{33}$ Furthermore, the composition and quality of the mature lymphocyte pool are badly shifted as individuals get older. It was not surprising to determine age as one of the predictors of mortality in such a disastrous disease. High D-dimer level has been consistently reported in COVID-19 cases and is also associated with worse prognosis. ${ }^{34}$ Induction of disseminated intravascular coagulation as a consequence of extended vascular endotheliitis explains the increased level of D-dimer. ${ }^{35}$ In a case-control study, Yao et ll $^{36}$ found that a D-dimer level of $>2.14 \mathrm{mg} / \mathrm{L}$ predicted in-hospital mortality, with sensitivity and specificity of $88.2 \%$ and $71.3 \%$, respectively. Increased levels of lactate dehydrogenase (LDH) manifest as an organ injury in such a systemic disease, concordant with the present study. ${ }^{37}$

A few points should be mentioned with regard to study limitations. First, the case number is not so high and the low case number might be the underlying reason for the lack of meaningful difference in inflammatory and clinical parameters between the study groups. Second, this is a retrospective study and thus potential bias cannot be excluded. Lastly, patients were not followed after hospital discharge to see if ACEI/ARB use has any potential effect on longterm follow-up of COVID-19 cases.

\section{CONCLUSION}

RAS blocker therapy seems to have neutral impact on the course of COVID-19. Populations with increased levels of D-dimer and CRP should be intensively monitored for their increased risk of mortality due to COVID-19.

Twitter Erhan Tenekecioglu @drercardio
Contributors Conceptualization: MK. Methodology: MK. Software: MK. Validation: MK. Formal analysis: MK. Investigation: MK. Data curation: ET. Writing - original draft preparation: ET and MK. Writing - review and editing: ET. Visualization: MK. Supervision: MK and ET. Guarantor: MK.

Funding The authors have not declared a specific grant for this research from any funding agency in the public, commercial or not-for-profit sectors.

Competing interests None declared.

Patient consent for publication Obtained.

Ethics approval This study involves human subjects and was approved by the Review Board of the Turkish Ministry of Health (ID: 2020/126; date: March 22,2020 ). The subjects gave informed consent to participate in the study before taking part.

Provenance and peer review Not commissioned; externally peer reviewed. Data availability statement Data may be obtained from a third party and are not publicly available.

Supplemental material This content has been supplied by the author(s). It has not been vetted by BMJ Publishing Group Limited (BMJ) and may not have been peer-reviewed. Any opinions or recommendations discussed are solely those of the author(s) and are not endorsed by BMJ. BMJ disclaims all liability and responsibility arising from any reliance placed on the content. Where the content includes any translated material, BMJ does not warrant the accuracy and reliability of the translations (including but not limited to local regulations, clinical guidelines, terminology, drug names and drug dosages), and is not responsible for any error and/or omissions arising from translation and adaptation or otherwise.

Open access This is an open access article distributed in accordance with the Creative Commons Attribution Non Commercial (CC BY-NC 4.0) license, which permits others to distribute, remix, adapt, build upon this work noncommercially, and license their derivative works on different terms, provided the original work is properly cited, an indication of whether changes were made, and the use is non-commercial. See: http://creativecommons.org/ licenses/by-nc/4.0/.

\section{ORCID iD}

Mustafa Kuzeytemiz http://orcid.org/0000-0002-3316-2490

\section{REFERENCES}

1 Rico-Mesa JS, White A, Anderson AS. Outcomes in patients with COVID-19 infection taking ACEI/ARB. Curr Cardiol Rep 2020;22:31.

2 Moon J-Y. Recent update of renin-angiotensin-aldosterone system in the pathogenesis of hypertension. Electrolyte Blood Press 2013;11:41-5.

3 Wu Z, McGoogan JM. Characteristics of and important lessons from the coronavirus disease 2019 (COVID-19) outbreak in China: summary of a report of 72314 cases from the chinese center for disease control and prevention. JAMA 2020;323:1239-42.

4 Hsu W-T, Galm BP, Schrank G, et al. Effect of renin-angiotensin-aldosterone system inhibitors on short-term mortality after sepsis: a population-based cohort study. Hypertension 2020;75:483-91.

5 Fletcher GF, Ades PA, Kligfield P, et al. Exercise standards for testing and training. Circulation 2013;128:873-934.

6 Morra ME, Van Thanh L, Kamel MG, et al. Clinical outcomes of current medical approaches for middle East respiratory syndrome: a systematic review and meta-analysis. Rev Med Virol 2018;28:e1977

7 Matsuyama R, Nishiura H, Kutsuna S, et al. Clinical determinants of the severity of middle East respiratory syndrome (MERS): a systematic review and metaanalysis. BMC Public Health 2016:16:1203.

8 Wang D, Hu B, Hu C, et al. Clinical characteristics of 138 hospitalized patients with 2019 novel coronavirus-infected pneumonia in Wuhan, China. JAMA 2020;323:1061-9

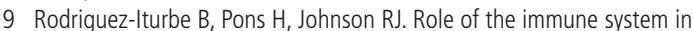
hypertension. Physiol Rev 2017;97:1127-64.

10 Dhaun N, Webb DJ. Endothelins in cardiovascular biology and therapeutics. Nat Rev Cardiol 2019;16:491-502.

11 Yahia F, Zakhama L, Ben Abdelaziz A. COVID-19 and cardiovascular diseases. scoping review study. Tunis Med 2020;98:283-94.

12 Hulot J-S. COVID-19 in patients with cardiovascular diseases. Arch Cardiovasc Dis 2020;113:225-6.

13 Kang Y, Chen T, Mui D, et al. Cardiovascular manifestations and treatment considerations in COVID-19. Heart 2020;106:1132-41.

14 Akhmerov A, Marbán E. COVID-19 and the heart. Circ Res 2020;126:1443-55. 
15 Guo J, Huang Z, Lin L, et al. Coronavirus disease 2019 (COVID-19) and cardiovascular disease: a viewpoint on the potential influence of AngiotensinConverting enzyme Inhibitors/Angiotensin receptor blockers on onset and severity of severe acute respiratory syndrome coronavirus 2 infection. J Am Heart Assoc 2020;9:e016219.

16 Huang C, Wang Y, Li X, et al. Clinical features of patients infected with 2019 novel coronavirus in Wuhan, China. Lancet 2020;395:497-506.

17 Wu C, Chen X, Cai Y, et al. Risk factors associated with acute respiratory distress syndrome and death in patients with coronavirus disease 2019 pneumonia in Wuhan, China. JAMA Intern Med 2020;180:934-43.

18 Kreutz R, Algharably EAE-H, Azizi M, et al. Hypertension, the renin-angiotensin system, and the risk of lower respiratory tract infections and lung injury: implications for COVID-19. Cardiovasc Res 2020;116:1688-99.

19 Ye M, Wysocki J, Naaz P, et al. Increased ACE 2 and decreased ACE protein in renal tubules from diabetic mice: a renoprotective combination? Hypertension 2004;43:1120-5.

20 Oudit GY, Crackower MA, Backx PH, et al. The role of ACE2 in cardiovascular physiology. Trends Cardiovasc Med 2003;13:93-101.

21 Crackower MA, Sarao R, Oudit GY, et al. Angiotensin-converting enzyme 2 is an essential regulator of heart function. Nature 2002;417:822-8.

22 Fagyas M, Úri K, Siket IM, et al. New perspectives in the renin-angiotensinaldosterone system (RaaS) II: albumin suppresses angiotensin converting enzyme (ACE) activity in human. PLoS One 2014;9:e87844.

23 Úri K, Fagyas M, Mányiné Siket I, et al. New perspectives in the renin-angiotensinaldosterone system (RaaS) IV: circulating ACE2 as a biomarker of systolic dysfunction in human hypertension and heart failure. PLoS One 2014;9:e87845.

24 Thomas MC, Pickering RJ, Tsorotes D, et al. Genetic ACE2 deficiency accentuates vascular inflammation and atherosclerosis in the APOE knockout mouse. Circ Res 2010;107:888-97.

25 Imai Y, Kuba K, Rao S, et al. Angiotensin-converting enzyme 2 protects from severe acute lung failure. Nature 2005;436:112-6.

26 Wang K, Gheblawi M, Oudit GY. Angiotensin converting enzyme 2: a doubleedged sword. Circulation 2020;142:426-8.
27 Liu Y, Yang Y, Zhang C, et al. Clinical and biochemical indexes from 2019$\mathrm{nCoV}$ infected patients linked to viral loads and lung injury. Sci China Life Sci 2020;63:364-74.

28 Wan Y, Shang J, Graham R, et al. Receptor recognition by the novel coronavirus from Wuhan: an analysis based on decade-long structural studies of SARS coronavirus. J Virol 2020;94. doi:10.1128/JVI.00127-20. [Epub ahead of print: 1703 2020].

29 Hoffmann M, Kleine-Weber H, Schroeder S, et al. SARS-CoV-2 cell entry depends on ACE2 and TMPRSS2 and is blocked by a clinically proven protease inhibitor. Cell 2020;181:271-80.

30 Furuhashi M, Moniwa N, Mita T, et al. Urinary angiotensin-converting enzyme 2 in hypertensive patients may be increased by olmesartan, an angiotensin II receptor blocker. Am J Hypertens 2015;28:15-21.

31 Batlle D, Wysocki J, Satchell K. Soluble angiotensin-converting enzyme 2: a potential approach for coronavirus infection therapy? Clin Sci 2020;134:543-5.

32 Ye R, Liu Z. ACE2 exhibits protective effects against LPS-induced acute lung injury in mice by inhibiting the LPS-TLR4 pathway. Exp Mol Pathol 2020;113:104350.

33 Jamieson BD, Douek DC, Killian S, et al. Generation of functional thymocytes in the human adult. Immunity 1999;10:569-75.

34 Gao Y, Li T, Han M, et al. Diagnostic utility of clinical laboratory data determinations for patients with the severe COVID-19. J Med Virol 2020;92:791-6.

35 Tang N, Li D, Wang X, et al. Abnormal coagulation parameters are associated with poor prognosis in patients with novel coronavirus pneumonia. J Thromb Haemost 2020;18:844-7.

36 Yao Y, Cao J, Wang Q, et al. D-dimer as a biomarker for disease severity and mortality in COVID-19 patients: a case control study. J Intensive Care 2020;8:49.

37 Henry BM, Aggarwal G, Wong J, et al. Lactate dehydrogenase levels predict coronavirus disease 2019 (COVID-19) severity and mortality: a pooled analysis Am J Emerg Med 2020;38:1722-6. 